\title{
Do changes in cigarette design influence the rise in adenocarcinoma of the lung?
}

\author{
David M. Burns • Christy M. Anderson • \\ Nigel Gray
}

Received: 11 July 2010/Accepted: 5 October 2010/Published online: 22 October 2010

(c) The Author(s) 2010. This article is published with open access at Springerlink.com

\begin{abstract}
Background Incidence rates for adenocarcinoma of the lung are increasing and are higher in the United States than in many other developed countries. We examine whether these trends may be associated with changes in cigarette design.

Methods Lung cancer risk equations based on observations during 1960-1972 from the American Cancer Society Cancer Prevention Study I are applied to 5-year birth cohort-specific estimates of changes in smoking behaviors to predict birth cohort-specific rates of squamous cell carcinoma and adenocarcinoma of the lung among US White men for the period 1973-2000. These expected rates are compared to observed rates for the same birth cohorts of White men in the US Surveillance, Epidemiology and End Results (SEER) data.

Results Changes in smoking behaviors over the past several decades adequately explain the changes in squamous cell carcinoma rates observed in the SEER data. However, predicted rates for adenocarcinoma do not match the observed SEER data without inclusion of a term increasing the risk for adenocarcinoma with the duration of smoking after 1965.

Conclusion The risk of developing squamous cell carcinoma from smoking appears to have remained stable in the United States over the past several decades; however, the
\end{abstract}

D. M. Burns $(\varangle)$. C. M. Anderson

UCSD School of Medicine, 1120 Solana Dr, Del Mar,

San Diego, CA 92014, USA

e-mail: dburns@ucsd.edu

N. Gray

Cancer Council of Victoria, Melbourne, VIC, Australia risk of adenocarcinoma has increased substantially in a pattern temporally associated with changes in cigarette design.

Keywords Cigarettes - Lung cancer - Changing risk · Changing cigarettes $\cdot$ Adenocarcinoma

\section{Introduction}

Adenocarcinoma of the lung has increased in the United States (US) over the past several decades both in terms of absolute incidence rates and as a fraction of all lung cancers [1-4]. In addition, incidence rates of adenocarcinoma of the lung in the United States are higher than those for many other developed countries [2] even though smoking prevalence rates are generally slightly lower in the United States. Several potential explanations for this increase have been examined and found not to explain the increase in adenocarcinoma including changes in the availability of diagnostic techniques such as bronchoscopy [5-7] and changes in criteria for histological classification [7].

The temporal association of this rise in adenocarcinoma with changes in cigarette design, and differences in cigarette design between the United States and some other countries raise questions about the contribution of changes in cigarette design and resultant composition of the smoke to the shift in the type of lung cancer from predominantly squamous cell to predominantly adenocarcinoma $[4,5,8-10]$.

Two large prospective mortality studies of lung cancer risk conducted by the American Cancer Society in the United States two decades apart reveal an increase in overall lung cancer risk among cigarette smokers from the 1960s to the 1980s even when adjusted for duration and intensity of cigarette smoking [5, 10]. The risk of 
adenocarcinoma of the lung, but not other types of lung cancer, also increased in smokers during the interval between these two studies [5]. In contrast, overall lung cancer risks for never smokers remain unchanged over time $[11,12]$, and rates of adenocarcinoma among never smokers were similar in the two studies [5].

Risk models derived from smoking behaviors and overall lung cancer mortality rates during the 1960s substantially underestimate current US lung cancer mortality rates ([13, 14] Burns et al., submitted). This underestimate can be corrected by adjusting for the duration of smoking after 1972 (Burns et al., submitted) suggesting that the increase in risk may be related to changes in the characteristics of the cigarettes smoked over time.

Rates of squamous cell carcinoma in Canada and Australia are similar to those of White men in the United States, but rates of adenocarcinoma are lower in Canada and Australia [2]. US style blended cigarettes have higher levels of tobacco-specific nitrosamines, organ-specific carcinogens for adenocarcinoma of the lung in animals [15], and US smokers have higher levels of biomarkers of exposure for tobacco-specific nitrosamines than smokers in Australia or Canada [16]. In addition, most lower yield cigarettes have ventilated filters that may lead to deeper inhalation and increased deposition of smoke in the alveolar regions of the lungs. These concerns are of particular importance as US style blended cigarettes gain market share in many countries where the WHO Framework Convention on Tobacco Control may create an opportunity to regulate these changes in cigarette design and composition.

We hypothesize that the increase in adenocarcinoma of the lung over time and differences between US adenocarcinoma rates and those of other countries may be due to differences in cigarette design and composition over time and across countries, and that the increase in the risk of adenocarcinoma contributes to an increase in overall lung cancer rates.

We examine whether smoking dose and duration-specific risk equations derived from the lung cancer mortality rates experienced in CPS I during the 1960s predict changes in US birth cohort-specific incidence of squamous cell carcinoma and adenocarcinoma of the lung during subsequent decades. We hypothesize that, if changes in the characteristics of cigarettes smoked result in a new and additional risk of adenocarcinoma, risk equations developed in the 1960s would continue to predict temporal changes in birth cohort-specific incidence of squamous cell lung cancer but would progressively underestimate birth cohort-specific incidence of adenocarcinoma as calendar year advanced. White men were selected for these analyses because CPS I has substantially fewer lung cancer deaths among women, or among African Americans, making the development of risk equations for smoking behaviors in the 1960s for these groups less reliable and more difficult to interpret.

\section{Methods}

Lung cancer risk model

Published risk equations derived from the lung cancer mortality experience of White men in the 12-year follow-up (1960-1972) of CPS I with terms for age, duration of smoking, and number of cigarettes smoked per day are used to estimate lung cancer risks for active smokers $[17,18]$. The form of these equations is as excess risk equations with the risk being the sum of the risk for never smokers and the excess risk produced by smoking $\left(R_{\mathrm{S}}=R_{\mathrm{NS}}+\mathrm{ERS}\right)$. Agespecific risks for never smokers are also derived from CPSI data [17]. The parameters used for the never smokers risk are $R_{\mathrm{NS}}=\left(9.21 e^{-13}\right) *\left(\operatorname{age}^{4.6}\right)$; and for the excess risk in smokers, the parameters are ERS $=\left(1.51 e^{-13}\right) *$ $\left(\operatorname{age}^{2.38}\right) *\left(\operatorname{cpd}^{0.867}\right) *\left(\right.$ dur $\left.^{2.87}\right)$. Excess risk equations, also based on CPS I data, and including a term for the duration of abstinence from smoking, are used to estimate risks for former smokers [17].

Birth cohort-specific estimates of smoking behavior

Estimates of smoking behaviors for White men in the US population were developed in conjunction with the National Cancer Institute Cancer Intervention and Surveillance Modeling Network (CISNET) and are available on the CISNET website. Using a dataset combining questions on smoking behavior from all of the National Health Interview Surveys from 1965 to 2005 and methods described elsewhere [19, 20], birth cohort-specific estimates for each calendar year between 1972 and 2000 are provided for rates of smoking initiation, prevalence of current and former smoking, the distribution of the duration of smoking for current and former smokers, the distribution of number of cigarettes smoked per day for current and former smokers, and the distribution of duration of abstinence for former smokers.

Observed and estimated lung cancer incidence rates

Incidence rates for cancer of the lung and bronchus among White men were obtained from SEER data by single year of age and by single calendar year from 1973 to 2003 using SEER*Stat software from three registries-SEER 9, 13, and 17. Lung cancer death rates for White men matching the following criteria were obtained: no prior cancer, confirmation by autopsy or death certificate only, clinical diagnosis only and in situ. They were categorized 
histologically by ICD-O-3 codes as follows: Small Cell (codes 8041-8045), Squamous (codes 8050-8089), Adenocarcinoma (codes 8140-8149, 8160, 8161, 8162, 8190-8221, 8260-8337, 8350-8551, 8570-8576, 89408941), and Large Cell (codes 8012-8014). Rates are generated by five-year birth cohorts for cohorts beginning with 1915-1919 and ending with 1950-1954 and for ages 40-75 years.

Birth cohort-specific estimates of lung cancer rates are generated by applying the risk equations for never, current, and former smokers to population estimates of smoking behavior for each calendar year. Smoking behaviors are arranged in cells specific for smoking status, duration of smoking, duration of abstinence, and cigarettes smoked per day; and lung cancer mortality rates are estimated for each cell using the risk equations developed from CPS I. A summary rate for the entire cohort in a given year is generated as the average (weighted by the fraction of the population in the cell) of the rates in all of the cells for that year.

These estimates of lung cancer rates are converted into estimates for each histological type by multiplying the estimated rates by the fraction of that histological type recorded by the SEER registry during the years 1973-1975. These proportions are $14.21 \%(n=1,779)$ for small cell, $36.71 \%(n=4,597)$ for squamous cell, $17.58 \%(n=2201$ for adenocarcinoma, $3.13 \%(n=392)$ for large cell, and $28.38 \%$ ( $n=3,554)$ for other. The result is type-specific estimates of lung cancer incidence based on smoking risks observed in the 1960s and type distributions from 1973 to 1975.

Adjustments to the estimates

\section{Difference between the mortality in CPS I and US mortality}

Lung cancer incidence for a healthy population such as that in CPS I is expected to be lower than that for the general US population [21]. Incidence rates are also higher than mortality rates. We use a power function to adjust the predicted mortality rates upward and fit them to the estimated birth cohort and calendar year-specific incidence rates in the SEER data from 1973 to 2000. By fitting the predicted rates to the observed SEER rates using non-linear regression, we derive parameters $a$, a constant, and $c$, the exponent of the power function. For the incidence of squamous cell lung cancer, the estimation equation becomes:

$$
\begin{aligned}
\mathrm{LC}_{\mathrm{SEER}}= & a \cdot\left\{\left[\left(\mathrm{NS} \cdot \mathrm{LC}_{\mathrm{NS}}\right)+\left(\mathrm{CS} \cdot \mathrm{LC}_{\mathrm{CS}}\right)+\left(\mathrm{FS} \cdot \mathrm{LC}_{\mathrm{FS}}\right)\right]\right. \\
& \cdot \text { SquamousProp }\}^{c}
\end{aligned}
$$

where NS, CS and FS are the proportions of never, current and former smokers in the birth cohort in a specified calendar year, and $\mathrm{LC}_{\mathrm{NS}}, \mathrm{LC}_{\mathrm{CS}}$ and $\mathrm{LC}_{\mathrm{FS}}$ are the weighted risks for those in that smoking status derived using the risk equations for predicting the incidence of lung cancer among never, current, and former smokers respectively in that calendar year.

\section{Differences due to increases in the risk of smoking}

An adjustment to capture the effect of an increased risk due to smoking after time $t_{0}$ is performed by incorporating a term increasing the risk with the number of years smoked after a specified calendar year $\left(t_{0}\right)$ for continuing smokers and former smokers. The equation for current smokers becomes:

$\widehat{R}_{\mathrm{S}}^{\prime}=\left[b\left(t-t_{0}\right)\right]^{I_{t}} \widehat{R}_{S}$

where

$I_{t}= \begin{cases}1, & b\left(t-t_{0}\right) \geq 1 \\ 0, & b\left(t-t_{0}\right)<1\end{cases}$

$\ddot{R}_{\mathrm{S}}=$ the lung cancer risk estimated from the CPS 1 risk equations for continuing smokers, $t=$ current calendar year, $t_{0}$ is the designated trigger year and $b$ is a constant.

Since the adjustment is intended to account for an increase in lung cancer risk over time, the adjustment for duration of smoking after $t_{0}$ is only applied in the equation when it is greater than or equal to 1 and therefore increases the predicted rate of lung cancer incidence.

The analogous equation for former smokers is:

$\widehat{R}_{\mathrm{FS}}^{\prime}=\left[b\left(t-t_{0}-t_{\mathrm{Q}}\right)\right]^{I_{t}} \widehat{R}_{\mathrm{FS}}$

$\ddot{R}_{\mathrm{FS}}=$ the lung cancer risk estimated from the CPS 1 risk equations for former smokers, and $t_{\mathrm{Q}}=$ the year in which the former smoker quits smoking.

When both the adjustment for a healthy population bias and the adjustment for increasing risk with advancing calendar year are applied, the resulting equation for adenocarcinoma is:

$$
\begin{aligned}
\mathrm{LC}_{\mathrm{SEER}}= & a \cdot\left\{\left[\left(\mathrm{NS} \cdot \mathrm{LC}_{\mathrm{NS}}\right)+\left(\mathrm{CS} \cdot \mathrm{LC}_{\mathrm{CS}} \cdot b \cdot \mathrm{S}_{\mathrm{CS}}\right)\right.\right. \\
& \left.\left.+\left(\mathrm{FS} \cdot \mathrm{LC}_{\mathrm{FS}} \cdot b \cdot \mathrm{S}_{\mathrm{FS}}\right)\right] \cdot \operatorname{propAdeno}\right\}^{c}
\end{aligned}
$$

The terms $\mathrm{S}_{\mathrm{SC}}$ and $\mathrm{S}_{\mathrm{FS}}$ are the durations of smoking in years after a specified calendar year in current and former smokers, respectively, and $b$ is the same constant for both groups. Non-linear regression is used to attempt estimation of the parameters $a, c$, and $b$ simultaneously; and when the models do not converge with the effort to simultaneously estimate $a, b$, and $c$, the values for $a$ and $c$ derived from the previous estimation of $a$ and $c$ in modeling US mortality data are used to derive $b$ alone, and then that value of $b$ is used to estimate new values for the parameters $a$ and $c$. Estimation of the parameters for different $t_{0}$ is performed 
manually by iterating $t_{0}$ in 5 -year increments while estimating one set of $a, b$, and $c$ for each increment until the variance, estimated by the mean squared error, was minimized.

\section{Results}

We have previously demonstrated that lung cancer mortality risks observed during the 1960 s progressively underestimate the observed US lung cancer mortality in White men as calendar year is advanced from 1960 to 2000 (Burns et al., submitted). This underestimate can be resolved by the introduction of a term for the duration of smoking after a specified calendar year suggesting that the lung cancer risks resulting from smoking may have increased over time. We now examine whether the same mortality risk equations derived from the lung cancer experience in the 1960s predict the changes in birth cohortspecific White male incidence of squamous cell and adenocarcinoma of the lung over the calendar year interval 1973-2000.

Risk equations from the CPS I data are applied to smoking behaviors of 5-year birth cohorts of White men born from 1915 to 1954 to generate birth cohort-specific risks of lung cancer mortality by single calendar year from 1973 to 2000. These overall lung cancer rates are converted to rates for the histological subtypes of lung cancer by multiplying them by the fraction of that subtype present in the SEER data for the years 1973-1975 (0.367 for squamous cell and 0.176 for adenocarcinoma). The predicted rates are then adjusted to match the observed rates for the same birth cohorts in the SEER population for the years 1973-2000.

Adjustment for differences between the CPS I population and the US population

Healthy population selection bias results in the observed disease rates for an epidemiological study such as the CPS I being lower than those for the general US population [21]. An adjustment for this underestimation is needed before examining the question of whether the type-specific lung cancer risks of smoking observed during the 1960s have changed over time. We use a power function to make this adjustment, and the resulting equation becomes:

Adjusted rate $=a *$ (cohort and year specific mortality rate estimate $*$ tumor type proportion $)^{c}$

The parameters $a$ and $c$ are derived by fitting the unadjusted predicted rates to the observed incidence for the histological subtypes in the US population derived from
SEER data. Since survival from lung cancer has changed only modestly over time, the adjustment for the difference between mortality and incidence rates is likely to be reasonably well approximated by the constant in the power function adjustment.

Incidence of squamous cell carcinoma and adenocarcinoma assuming no change in risk over time

For squamous cell carcinomas, the resulting parameter value for the constant $(a)$ in the power function is 0.66 and the exponent $(c)$ is 1.23 . The fraction of all SEER lung cancers that are squamous cell during the years 1973-1975 is 0.367 .

Figure 1 is an identity plot comparing the birth cohort and calendar year-specific estimates of squamous cell carcinoma adjusted for healthy population bias to the birth cohort and calendar year-specific rates for the SEER population. The adjusted estimates match the SEER data well, particularly given the relatively simple form of the adjustment. This suggests that, for squamous cell carcinoma, there has been little change in the risk of smoking since the 1960s and that change in smoking behaviors over time adequately explain changes in incidence rates.

Figure 2 presents comparable data for adjusted estimates of adenocarcinoma of the lung. The same process was used to estimate incidence rates for adenocarcinoma. When the parameters for the power function are estimated by fitting the data, the constant $(a)$ is 3.13 and the exponent (c) is 0.99 . The comparison of adjusted estimates to the SEER rates in Fig. 2 demonstrates a poor fit with the lower rates being below the line of identity and the higher rates

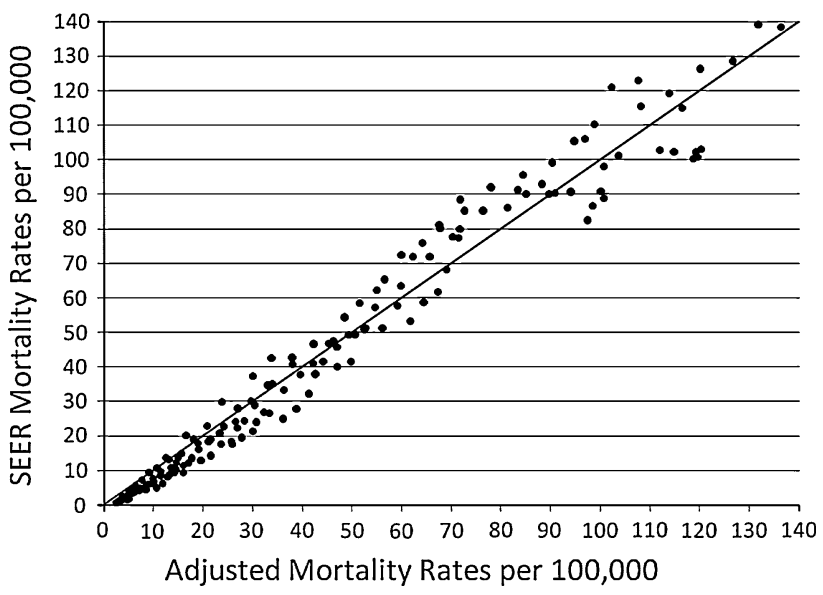

Fig. 1 Comparison of SEER squamous cell carcinoma incidence rates for 5-year birth cohorts of White men by single calendar year from 1973 to 2000 to the estimates using the CPS I risk equations and the adjustments described previously, but with no adjustment for years of smoking after 1950 


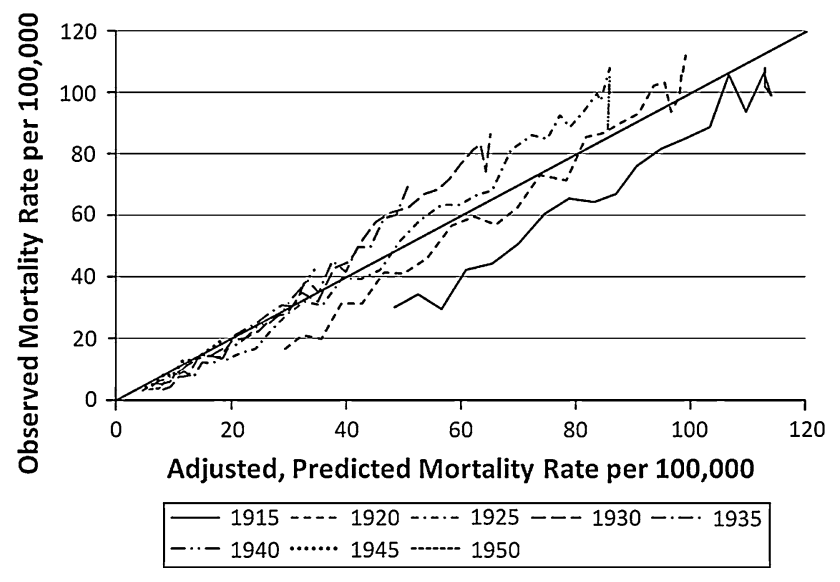

Fig. 2 Comparison of SEER adenocarcinoma incidence rates for 5-year birth cohorts of White men by single calendar year from 1973 to 2000 to the estimates using the CPS I Risk equations and the adjustments described previously, but with no adjustment for years of smoking after 1950

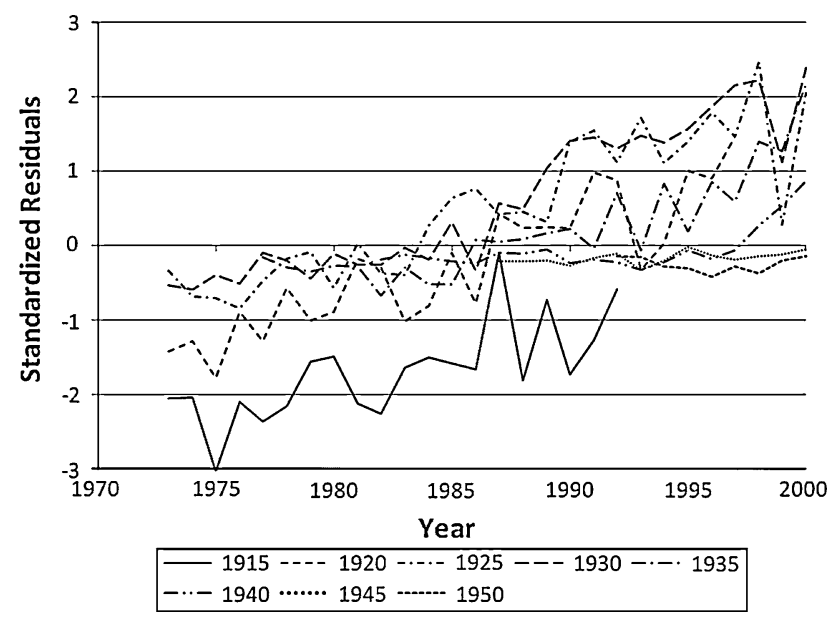

Fig. 3 Standardized residuals for the difference between SEER and predicted rates of adenocarcinoma of the lung without adjustment for calendar year plotted by calendar year

being distributed around the line. There is also a pattern where the difference between the estimated and SEER rates differs systematically by birth cohort.

In order to further examine this pattern, we plotted the standardized residual error for this comparison by the calendar year of the observation (Fig. 3). There is a clear positive trend for the standardized residuals with advancing calendar year suggesting that a calendar year term would improve the prediction of incidence rates for adenocarcinoma. These observations suggest that adenocarcinoma incidence, in contrast to squamous cell incidence, is not well predicted by the risk estimates obtained in the 1960s and that the error in estimation changes as a function of advancing calendar year.
We also examined the residual error with age. While the magnitude of the standardized residuals increased with advancing age, they did not show a directional trend with age for either squamous cell or adenocarcinoma. Residual errors for squamous cell plotted against calendar year showed a very small negative trend (i.e., the opposite direction of that for adenocarcinoma) with advancing calendar year.

\section{Adjustment for changing risk over time}

The strong trend with calendar year for adenocarcinoma in Fig. 3 and the need to adjust predicted mortality rates for an increase in the risk of smoking with advancing calendar year(Burns et al., submitted) led us to add an adjustment to the estimated adenocarcinoma incidence for the duration of smoking after specified calendar years. In order to adjust for the increasing risk over time suggested by Fig. 3, a term that multiplies a constant $(b)$ by the duration of smoking after a specified calendar year $(S)$ was added to the predictive equations for current and former smokers. That equation becomes:

$$
\begin{aligned}
\mathrm{LC}_{\mathrm{SEER}}= & a \cdot\left\{\left[\left(\mathrm{NS} \cdot \mathrm{LC}_{\mathrm{NS}}\right)+\left(\mathrm{CS} \cdot \mathrm{LC}_{\mathrm{CS}} \cdot b \cdot \mathrm{S}_{\mathrm{CS}}\right)\right.\right. \\
& \left.\left.+\left(\mathrm{FS} \cdot \mathrm{LC}_{\mathrm{FS}} \cdot b \cdot \mathrm{S}_{\mathrm{FS}}\right)\right] \cdot \text { PropAdeno }\right\}^{c}
\end{aligned}
$$

An effort was made to simultaneously derive the values for $a, b$, and $c$ by fitting the estimated rates to the SEER data, but the solution would not converge in a range of reasonable values. We then undertook a two-step solution. The first step was to utilize the values for $a$ and $c$ identified for the fit of total lung cancer mortality to the US mortality data ( 0.78 for $a$ and 1.13 for $b$ ) and then derive values for $b$. This process was conducted for different calendar years for starting the measurement of duration in the $S$ term of the equation above by sequentially deriving values for $b$ for 5 -year sequential iterations of specified calendar years and examining the goodness of fit for the resulting predicted incidence. The results of these efforts are presented in Table 1, and the target year providing the best fit is 1950 with the $b$ term equaling 0.06791 .

A second step then utilized the value for the $b$ parameter for the year 1950 in Table 1 and derived new values for the $a$ and $c$ parameters by fitting the estimated adenocarcinoma rates to the SEER adenocarcinoma rates. The resulting value for $a$ is 1.7593 , and the value for $c$ is 0.9243 (MSE $=15.9039, F=15,435.8$ ). The adjustment for calendar year is only applied when the term multiplying $b$ and the number of years of smoking after 1950 exceeds one and therefore only begins to adjust the rates after 1965 and 15 years of duration of smoking. Since the SEER data are limited to years after 1973 and the risks of adenocarcinoma are only estimated for individuals above age 40 , essentially 
Table 1 Values of parameter $b$ at different starting years for measuring the duration in the $S$ term and using the values of $a$ and $c$ derived from the fit of the squamous cell data

${ }^{a}$ Best fit

\begin{tabular}{llll}
\hline Adjusted for years smoked after $\rightarrow$ & 1945 & $1950^{\mathrm{a}}$ & 1955 \\
\hline$b$ & 0.06054 & 0.06791 & 0.07798 \\
MSE & $8.328782 \mathrm{E}-8$ & $5.946912 \mathrm{E}-8$ & $5.974554 \mathrm{E}-8$ \\
$F$ & $1,0351.2$ & $14,528.1$ & $14,401.5$ \\
Adjusted $r^{2}$ & 0.9843 & 0.9888 & 0.9887 \\
AIC & $-2,688.66$ & $-2,744.24$ & $-2,743.48$ \\
\hline
\end{tabular}

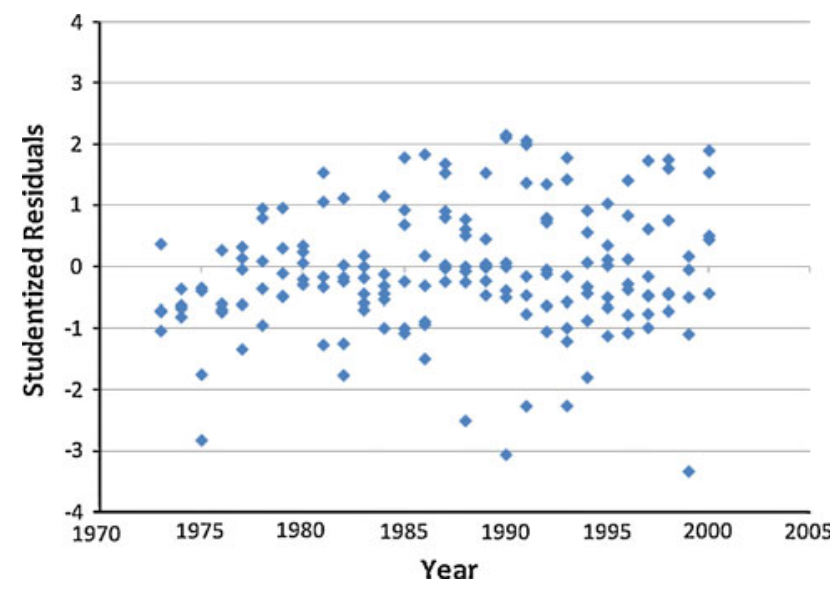

Fig. 5 Standardized residuals for the difference between SEER and predicted rates of adenocarcinoma of the lung plotted by calendar year

developing squamous cell carcinoma has remained unchanged.

We also examined whether adding a term for duration of smoking after specified calendar years improved the fit for squamous cell carcinoma estimates. The introduction of a term for duration of smoking after 1950 for squamous cell lung cancer incidence did not substantively improve the fit of the data.

\section{Discussion}

Our analyses demonstrate that changes in birth cohortspecific rates of squamous cell carcinoma of the lung over the last several decades are adequately explained by changes in smoking behaviors indicating that the risk of smokers developing squamous cell carcinoma of the lung has remained unchanged across a period during which substantial changes in cigarette design were implemented. In contrast, the risk of smoking for adenocarcinoma has increased and the prediction of birth cohort-specific rates is enhanced by adjusting for an increasing toxicity of the cigarettes smoked over time. The constant predictive relationships between smoking behaviors and squamous cell carcinoma rates over time coupled with an increasing risk of smoking behaviors for adenocarcinoma suggest that the increase in adenocarcinoma as a proportion of all lung 

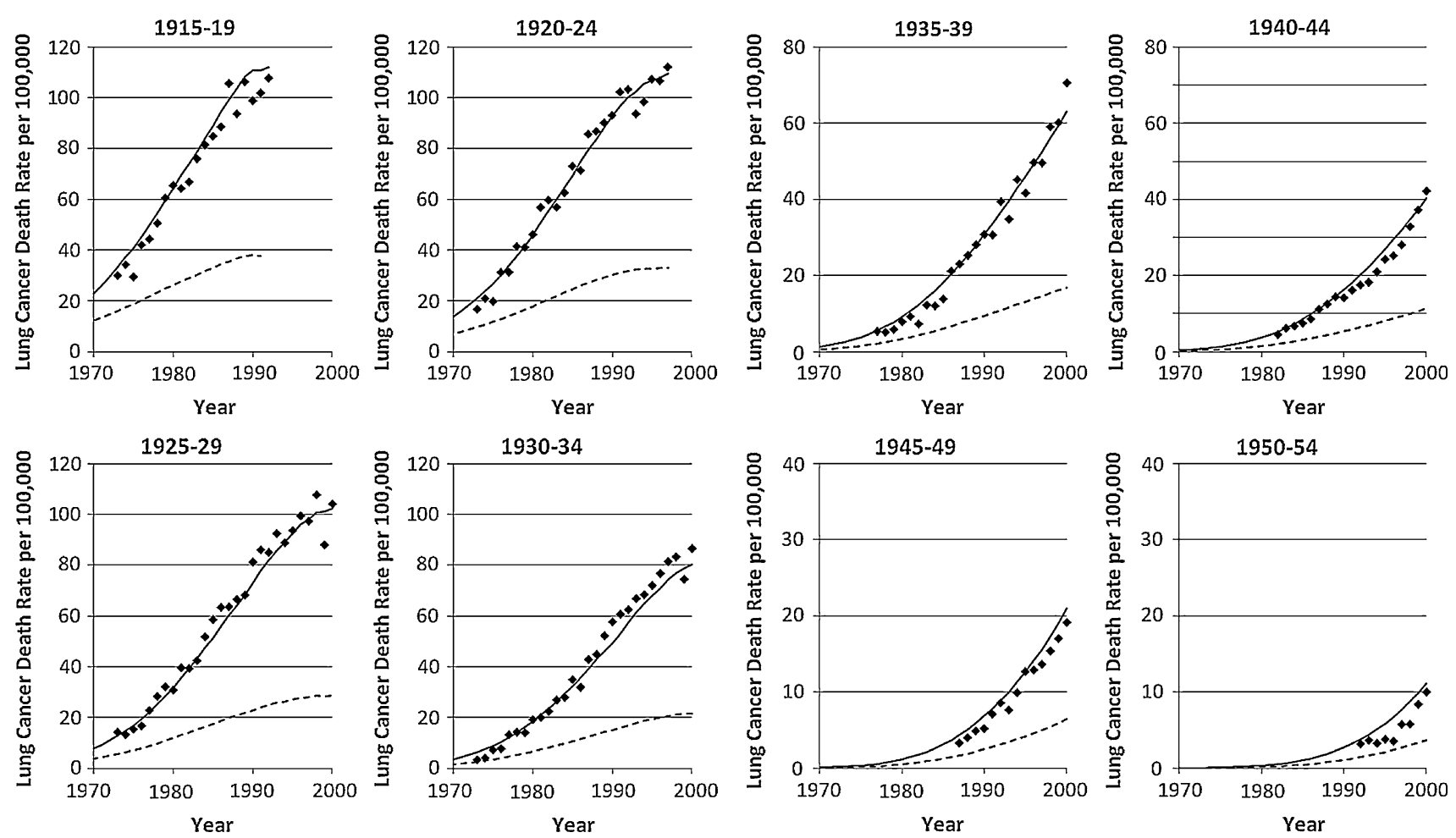

Fig. 6 Comparison of predicted and observed birth cohort-specific rates of adenocarcinoma of the lung for White men by calendar year. The dashed lines are the unadjusted predicted rates, the solid lines are the adjusted rates, and the points are the values derived from the SEER data

cancers is likely due to an increase in the capacity of the cigarettes smoked to cause adenocarcinoma rather than a shift in tumor type from squamous cell to adenocarcinoma.

While changes in histological classification and diagnostic techniques may have made modest contribution to the increase in adenocarcinoma of the lung in the United States, it is generally recognized that they do not explain the magnitude of the observed change [5-7]. Shifts in the age distribution of the population over time can increase age-adjusted adenocarcinoma rates, but they would not have a meaningful impact on the birth cohort-specific rates we present. Shifts in the socioeconomic distribution of smokers over time could contribute to an increase in overall lung cancer death rates, but it is more difficult to understand how they would explain the shift toward adenocarcinoma. The limited analyses that address this issue suggest that shifts in the social class of smokers have less effect on trends in adenocarcinoma than for the other types of lung cancer [22]. Air pollution, specifically oxides of nitrogen, has been suggested as a cause of the rise in adenocarcinoma of the lung in the United States [23-25], but the absence of a change in adenocarcinoma rates among never smokers in the two American Cancer Society studies [5] conducted more than 20 years apart makes this hypothesis less likely.

Our results are consistent with other evidence on risk of adenocarcinoma over time. Early in the examination of the lung cancer epidemic, the most common lung cancer in men was squamous cell and the relative risks of smoking for squamous cell were substantially higher than for adenocarcinoma [26, 27]. There was even considerable debate as to whether adenocarcinoma was associated with cigarette smoking [28]. With the rise in the frequency of adenocarcinoma over time, the relative risks for adenocarcinoma associated with smoking also increased [5, 29], suggesting that a new or substantially enhanced risk of developing adenocarcinoma of the lung was manifesting itself in smokers. This contrasts with a constant rate of overall lung cancer, and of adenocarcinoma, among never smokers over time $[5,11,12]$. When the relative risks of smoking for the development of adenocarcinoma of the lung were compared in the two American Cancer Society Cancer Prevention Studies, the relative risk among smokers for adenocarcinoma increased from 4.6 for men and 1.5 for women in CPS I conducted in the 1960s to 19.0 for men and 8.1 for women in CPS II conducted in the 1980s [5]. Among never smokers, the age-adjusted death rates for adenocarcinoma of the lung were essentially unchanged among never smokers when the data for CPS I and II were compared [5].

Time trends for age-standardized rates of squamous cell and adenocarcinoma of the lung are different in the United States [3, 30]. Age-adjusted rates of squamous cell carcinoma began to decline among White men in the early to mid 1980s, whereas rates of adenocarcinoma continued to 
increase for another $10-15$ years $[3,30]$. The differences in time trends for adenocarcinoma and squamous cell carcinoma could be due to a difference in the relationship of age to squamous cell and adenocarcinoma incidence. Our analyses address the possibility that the divergence is due to differences in the relationship with age by demonstrating that the effect with calendar year is present even when age and birth cohort are specified in the analyses and that agespecific risks increase across sequential cohorts. Differences in adenocarcinoma trends could also be due to differences in the time course of declines in risk following cessation for the different tumor types [31]; but if this effect explained our findings, the effect should be greatest at older ages where the prevalence of former smokers is greater. Our results demonstrate a greater effect at younger ages.

There have been substantial changes in cigarette design and manufacture over to past several decades [32]. Two principal mechanisms by which changes in cigarette design can alter the risks of smoking have been suggested and they may act together $[4,5]$. The increase in puff volume and depth of inhalation observed among smokers of lower tar yield cigarettes might increase the exposure of lung alveolar cells to the carcinogens in smoke. Modeling of smoke deposition in the lungs of smokers resulting from compensatory changes in smoking behavior suggests that this effect is likely to occur, but the magnitude of the effect may not be large enough to explain the observed shift to adenocarcinoma [33]. A second mechanism is an increase in the levels of tobacco-specific nitrosamines in US cigarettes over time [8, 32]. Tobacco-specific nitrosamines are organ-specific carcinogens for adenocarcinoma of the lung in animals [8], and biomarkers of tobacco-specific nitrosamines in the urine predict the risk of lung cancer in smokers even after controlling for the intensity and duration of smoking [34, 35]. Levels of tobacco-specific nitrosamine biomarkers are also associated with an increased risk for adenocarcinoma but not other types of lung cancer [35]. Widespread shift to filtered cigarettes occurred in the 1950s, and changes in the nitrosamine levels date at least from the 1960s [32, 36].

Higher levels of tobacco-specific nitrosamines largely result from the inclusion of burley tobacco in US style blended cigarettes, and lower levels of these nitrosamines are found in the unblended flue-cured tobacco used in cigarettes sold in the United Kingdom, Canada, and Australia, with the lowest levels found in Australia [37]. Biomarkers of exposure in smokers confirm these differences across countries in cigarettes translate into differences in smoker exposures to tobacco-specific nitrosamines [16].

In England [22] and in Scotland [38], incidence rates for adenocarcinoma of the lung in men have been increasing only slightly and squamous cell carcinoma remains the predominant form of lung cancer in men.
Rates for squamous cell carcinoma are similar for men in the United States and Canada [2]. However, Canadian male adenocarcinoma incidence rates remain lower than those for squamous cell and are well below the adenocarcinoma incidence for White men in the United States [2].

Figure 7 presents adenocarcinoma as a percentage of the four major types of lung cancer for sequential birth cohorts in the United States and Australia. While there appears to be a small increase in the proportion of lung cancer i.e. adenocarcinoma across sequential cohorts in the Australian data, particularly for recent cohorts of women, the magnitude of the trend and the absolute proportion i.e. adenocarcinoma are substantially lower in Australia than in the United States. Of note, the earliest birth cohorts in the United States, who would have had the longest exposure to cigarettes with lower nitrosamine levels, appear to have proportions of adenocarcinoma similar to the average of all cohorts in Australia.

\section{Limitations of the analyses}

The most substantive limitation of these analyses is that they lack individual-level data directly linking smoking behaviors and lung cancer occurrence. As such, they can only generate hypotheses rather than establish causality.

While the results presented may appear to be an effort to produce a model of lung cancer risk, our intent was quite different. Our analyses examine smoking behaviors related to lung cancer risk and generate simple predictive equations using those factors with the intent of examining whether the predictive validity of these factors has changed over time. Almost certainly additional adjustments could lead to a better fit of the data, and far more complex risk models have been published, but our intent was to examine the effects of calendar year on lung cancer risk due to smoking rather than to develop the ideal model for predicting risk.

We also examined the SEER incidence rates for smallcell and large-cell carcinoma using the same methods. In general, the analysis of small cell incidence was similar to that for squamous cell and the analysis of large cell resembled that of adenocarcinoma, but the smaller number of observations and variability of the incidence rates by calendar year within the same birth cohort led to uncertainty as to the appropriate interpretation of these results and therefore we have not reported them.

Analyses of US lung cancer mortality trends over time using a similar approach suggest that the risk of smoking has increased over the past several decades, and the analyses presented in this paper suggest that an increasing risk of adenocarcinoma makes a substantive contribution to that increase in risk. If the increases in adenocarcinoma seen in our analyses are the result of changes in cigarette design 
Fig. 7 Australian and US adenocarcinoma as a proportion of designated lung cancers. Data for the Australian national cancer registry provided by Helen Farrugia, Director Information Systems, Cancer Epidemiology Centre, The Cancer Council Victoria

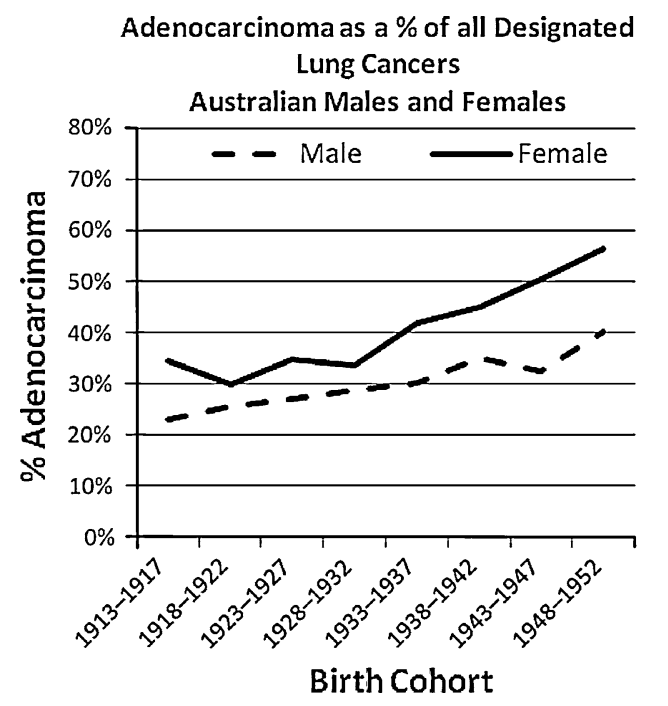

Adenocarcinoma as a \% of all Designated Lung Cancers

US White Males and Females

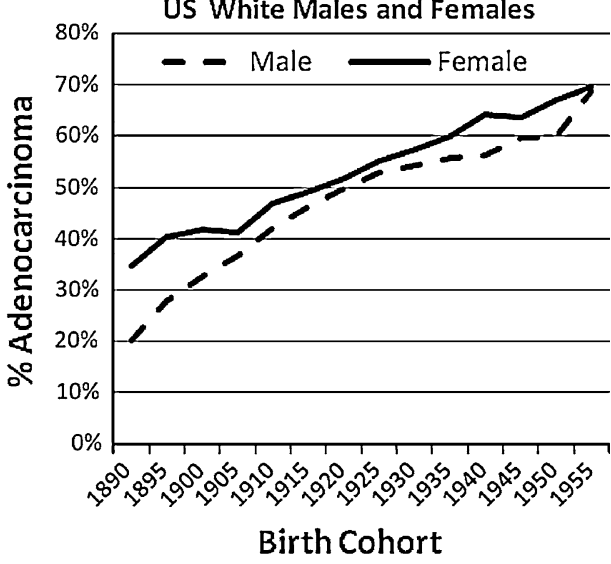

over the past several decades, they may have been avoidable. Perhaps more important currently, if these changes can be identified, they may also be reversible with the Food and Drug Administration jurisdiction over cigarette-manufacturing processes and they may be avoidable in other countries through regulatory control of tobacco products under the WHO Framework Convention on Tobacco Control.

Acknowledgments We would like to acknowledge the advice and support of Michael Thun of the American Cancer Society in providing access to the CPS I data and reviewing the manuscript and of Helen Farrugia, Director Information Systems, Cancer Epidemiology Centre, The Cancer Council Victoria for providing the data for the Australian national cancer registry. This work was supported by contracts from the National Cancer Institute 263-MQ-320522 and 263-MQ-414669 and the Tobacco Control Research and Education Foundation.

Conflict of interest David Burns has testified extensively in tobacco litigation against the tobacco industry including in litigation on the risks of low-tar cigarettes. Christy Anderson: none. Nigel Gray: none. The Tobacco Control Research and Education Foundation has received an unrestricted gift from attorneys who were involved in tobacco litigation against the tobacco industry that led to the Master Settlement Agreement. The gift was from fees they earned in that litigation and the law firm, which made the gift is not currently involved in tobacco litigation.

Open Access This article is distributed under the terms of the Creative Commons Attribution Noncommercial License which permits any noncommercial use, distribution, and reproduction in any medium, provided the original author(s) and source are credited.

\section{References}

1. Devesa SS, Shaw GL, Blot WJ (1991) Changing patterns of lung cancer incidence by histological type. Cancer Epidemiol Biomarkers Prev 1(1):29-34
2. Devesa SS, Bray F, Vizcaino AP, Parkin DM (2005) International lung cancer trends by histologic type: male:female differences diminishing and adenocarcinoma rates rising. Int $\mathrm{J}$ Cancer 117(2):294-299

3. Wingo PA, Ries LA, Giovino GA, Miller DS, Rosenberg HM, Shopland DR et al (1999) Annual report to the nation on the status of cancer, 1973-1996, with a special section on lung cancer and tobacco smoking. J Natl Cancer Inst 91(8):675-690

4. Wynder EL, Muscat JE (1995) The changing epidemiology of smoking and lung cancer histology. Environ Health Perspect 103(Suppl 8):143-148

5. Thun MJ, Lally CA, Flannery JT, Calle EE, Flanders WD, Heath CW Jr (1997) Cigarette smoking and changes in the histopathology of lung cancer. J Natl Cancer Inst 89(21): $1580-1586$

6. Zheng T, Holford TR, Boyle P, Chen Y, Ward BA, Flannery J et al (1994) Time trend and the age-period-cohort effect on the incidence of histologic types of lung cancer in Connecticut, 1960-1989. Cancer 74(5):1556-1567

7. Charloux A, Quoix E, Wolkove N, Small D, Pauli G, Kreisman H (1997) The increasing incidence of lung adenocarcinoma: reality or artefact? A review of the epidemiology of lung adenocarcinoma. Int J Epidemiol 26(1):14-23

8. Hoffmann D, Rivenson A, Hecht SS (1996) The biological significance of tobacco-specific N-nitrosamines: smoking and adenocarcinoma of the lung. Crit Rev Toxicol 26(2):199-211

9. Gabrielson E (2006) Worldwide trends in lung cancer pathology. Respirology 11(5):533-538

10. Thun MJ, Heath CW Jr (1997) Changes in mortality from smoking in two American Cancer Society prospective studies since 1959. Prev Med 26(4):422-426

11. Thun MJ, Hannan LM, Adams-Campbell LL, Boffetta P, Buring JE, Feskanich D et al (2008) Lung cancer occurrence in neversmokers: an analysis of 13 cohorts and 22 cancer registry studies. PLoS Med 5(9):e185

12. Thun MJ, Henley SJ, Burns D, Jemal A, Shanks TG, Calle EE (2006) Lung cancer death rates in lifelong nonsmokers. J Natl Cancer Inst 98(10):691-699

13. Stevens RG, Moolgavkar SH (1984) A cohort analysis of lung cancer and smoking in British males. Am $\mathrm{J}$ Epidemiol 119(4):624-641

14. Tolley HD, Crane L, Shipley N (1991) Smoking prevalence and lung cancer death rates. In: Shopland D, Burns DM, Samet JM, Gritz ER (eds) Strategies to control tobacco use in the United 
States: a blueprint for public health action in the 1990s. National Cancer Institute, Bethesda, pp 75-144

15. IARC Working Group on the Evaluation of Carcinogenic Risks to Humans (2004: Lyon France), International Agency for Research on Cancer (2007) Smokeless tobacco and some tobacco-specific N-nitrosamines. World Health Organization distributed by WHO Press, Lyon, France, Geneva, Switzerland

16. Ashley DL, O'Connor RJ, Bernert JT, Watson CH, Polzin GM, Jain RB et al. Effect of differing levels of tobacco-specific nitrosamines in cigarette smoke on the levels of biomarkers in smokers. Cancer Epidemiol Biomarkers Prev

17. Knoke JD, Burns DM, Thun MJ (2008) The change in excess risk of lung cancer attributable to smoking following smoking cessation: an examination of different analytic approaches using CPS-I data. Cancer Causes Control 19(2):207-219

18. Knoke JD, Shanks TG, Vaughn JW, Thun MJ, Burns DM (2004) Lung cancer mortality is related to age in addition to duration and intensity of cigarette smoking: an analysis of CPS-I data. Cancer Epidemiol Biomarkers Prev 13(6):949-957

19. Burns DM, Lee LL, Gilpin B, Tolley HD, Vaughn J, Shanks T (1997) Cigarette smoking behavior in the United States. In: Burns DM, Garfinkel L, Samet JM (eds) Changes in cigarette related disease risks and their implications for prevention and control. National Cancer Institute, Bethesda, pp 13-112

20. Anderson CM, Burns DM, Dodd K, Feuer EJ (2010) Birth cohort specific estimates of smoking behaviors for the U.S. population risk analysis (submitted)

21. Pinsky PF, Miller A, Kramer BS, Church T, Reding D, Prorok P et al (2007) Evidence of a healthy volunteer effect in the prostate, lung, colorectal, and ovarian cancer screening trial. Am J Epidemiol 165(8):874-881

22. Bennett VA, Davies EA, Jack RH, Mak V, Moller H (2008) Histological subtype of lung cancer in relation to socio-economic deprivation in South East England. BMC Cancer 8:139

23. Chen F, Bina WF, Cole P (2007) Declining incidence rate of lung adenocarcinoma in the United States. Chest 131(4):1000-1005

24. Chen F, Cole P, Bina WF (2007) Time trend and geographic patterns of lung adenocarcinoma in the United States, 1973-2002. Cancer Epidemiol Biomarkers Prev 16(12):2724-2729

25. Chen F, Jackson H, Bina WF (2009) Lung adenocarcinoma incidence rates and their relation to motor vehicle density. Cancer Epidemiol Biomarkers Prev 18(3):760-764

26. United States Public Health Service, Office of the Surgeon General, National Center for Chronic Disease Prevention and Health Promotion (U.S.) (2004) The health consequences of smoking a report of the Surgeon General. U.S. Public Health Service, National Center for Chronic Disease Prevention and Health Promotion, Atlanta. Available from: http://purl.access.gpo. gov/GPO/LPS49585

27. Wu-Williams AH, Samet JM (1994) Lung cancer and cigarette smoking. In: Samet JM (ed) Epidemiology of lung cancer. Marcel Decker, New York, pp 71-108

28. Kreyberg L (1962) Histological lung cancer types. A morphological and biological correlation. Acta Pathol Microbiol Scand Suppl 157:1-92

29. United States Department of Health and Human Services, Office on Women's Health (2001) Surgeon General's report on women and smoking. Hispanic women and smoking. Office on Women's Health, Washington, DC. Available from: http://purl.access. gpo.gov/GPO/LPS38833

30. Travis WD, Lubin J, Ries L, Devesa S (1996) United States lung carcinoma incidence trends: declining for most histologic types among males, increasing among females. Cancer 77(12): 2464-2470

31. Kenfield SA, Wei EK, Stampfer MJ, Rosner BA, Colditz GA (2008) Comparison of aspects of smoking among the four histological types of lung cancer. Tob Control 17(3):198-204

32. Hoffmann D, Hoffmann I (1997) The changing cigarette, 1950-1995. J Toxicol Environ Health 50(4):307-364

33. Gower S, Hammond D (2007) CSP deposition to the alveolar region of the lung: implications of cigarette design. Risk Anal 27(6):1519-1533

34. Church TR, Anderson KE, Caporaso NE, Geisser MS, Le CT, Zhang Y et al (2009) A prospectively measured serum biomarker for a tobacco-specific carcinogen and lung cancer in smokers. Cancer Epidemiol Biomarkers Prev 18(1):260-266

35. Yuan JM, Koh WP, Murphy SE, Fan Y, Wang R, Carmella SG et al (2009) Urinary levels of tobacco-specific nitrosamine metabolites in relation to lung cancer development in two prospective cohorts of cigarette smokers. Cancer Res 69(7):2990-2995

36. Thun MJ, Burns DM (2001) Health impact of "reduced yield" cigarettes: a critical assessment of the epidemiological evidence. Tob Control 10(Suppl 1):i4-i11

37. WHO (2008) (TobReg) SGoTPR. The scientific basis of tobacco product regulation. World Health Organisation Technical Report Series (951), pp 1-277 (1 p following)

38. Harkness EF, Brewster DH, Kerr KM, Fergusson RJ, MacFarlane GJ (2002) Changing trends in incidence of lung cancer by histologic type in Scotland. Int J Cancer 102(2):179-183 